\title{
O perfil das questões de ciências naturais do novo Enem: interdisciplinaridade ou contextualização?
}

\section{The profile of natural sciences in new Enem questions: interdisciplinarity or contextualization?}

João Paulo Stadler ${ }^{1}$. Fabiana Roberta Gonçalves e Silva Hussein ${ }^{1}$

\begin{abstract}
Resumo: Investigar o perfil das questões de Ciências Naturais (CN) do Novo Enem constitui um papel importante para compreender o ensino desta área em sala de aula, tendo em vista a importância atribuída ao exame no planejamento da prática docente. Com o emprego da análise de conteúdo categorial, balizada pelos conteúdos descritos nos PCN+ e nos livros do PNLD, foi possível classificar as questões de CN do Novo Enem de 2009 a 2014 de acordo com a presença de interdisciplinaridade ou contextualização em seus enunciados. Após a análise, foi possível perceber que, em contrariedade aos pressupostos, a avaliação do Novo Enem é predominantemente disciplinar (contextual) e que existem questões que apresentam um caráter altamente interdisciplinar, não observado na prática docente. Em suma, é necessário que haja coesão entre o que é delimitado, ensinado e cobrado dos alunos.
\end{abstract}

Palavras-chave: Enem. Interdisciplinaridade. Contextualização. Ciências naturais. Análise de conteúdo.

\begin{abstract}
In investigating the profile of natural sciences New Enem questions have an essential role in understand the teaching of this subject in the classroom, considering the importance given to the exam during the planning of teaching. By using categorical content analysis, delimitated by $\mathrm{PCN}+$ contents and PNLD textbooks, it was possible to categorize natural sciences New Enem questions presented between 2009 and 2014, according to the presence of Interdisciplinarity or Contextualization. It was possible to realize that, despite the official parameters, the exam is mainly disciplinary (contextual), even though there were questions which present an interdisciplinary character, they were not observed in the teachers' practice. In short, it is necessary to establish cohesion between what is taught and examined in the students' tests.
\end{abstract}

Keywords: Enem. Interdisciplinarity. Contextualization. Natural sciences. Contents analysis.

\footnotetext{
${ }^{1}$ Universidade Tecnológica Federal do Paraná (UTFPR), Curitiba, PR, Brasil. E-mail: <jp.stadler@gmail.com>.
} 


\section{Introdução}

O Ensino Médio é uma etapa da Educação Básica que apresenta uma gama variada de objetivos, entre os quais encontra-se a possibilidade de acesso ao Ensino Superior (BRASIL, 1996). Considerando este aspecto, é interessante observar que o Exame Nacional do Ensino Médio (Enem), em especial após sua reformulação em 2009, apresenta-se como um meio de acesso ao Ensino Superior bastante importante, pois possibilita que o estudante, após realizar um único exame, concorra a vagas potenciais em universidades públicas e privadas por meio de diferentes programas. Deste modo, o Enem tem figurado como assunto de discussão entre os docentes, discentes e responsáveis. Tal fato tende a indicar que os professores estão aptos a considerar a avaliação na construção do planejamento de sua prática docente, o que justifica o estudo detalhado do exame.

Outro ponto amplamente discutido, durante a formação inicial e continuada dos professores, é a questão da interdisciplinaridade e da contextualização dos conteúdos a serem trabalhados em sala de aula como uma maneira de torná-los mais interessantes e próximos aos estudantes. Apesar da inexistência de uma uniformidade no tocante à definição de interdisciplinaridade e contextualização e, por conseguinte, dos limites de cada uma das abordagens, há estudos (conforme discutido no terceiro item) que corroboram com a ideia de que uma prática docente mais próxima da realidade do estudante, seja por contextualização ou interdisciplinaridade, apresenta resultados positivos em termos de motivação e aprendizagem.

Combinando estes dois pontos de discussão, é interessante entender como as avaliações do Novo Enem apresentam elementos que remetam às abordagens citadas e, em contraparti$\mathrm{da}$, se uma abordagem contextual ou interdisciplinar poderia influenciar na desenvoltura dos estudantes na realização do exame, aumentando suas chances de ingresso no Ensino Superior.

Esta maneira de pensar, para alguns, é controversa, pois consideram que não é função do professor preparar os alunos para um exame específico, mas ensinar os conteúdos de maneira efetiva. É importante salientar que este trabalho não pretende estipular que o Novo Enem deva ser o limitador do trabalho docente, sua origem e seu fim. Pensando de outra maneira, é defendido aqui que uma prática que possa abarcar elementos contidos no exame ao planejamento e prática docente, sem se distanciar de seus objetivos, pode resultar em um melhor desempenho dos alunos no teste como um objetivo extra aos já pretendidos pelo docente.

Sendo assim, este trabalho pretendeu classificar as questões de Ciências Naturais do Novo Enem (de 2009 a 2014) em duas categorias: interdisciplinar e contextual. A escolha dessas categorias deveu-se ao fato de que os documentos norteadores para a elaboração da prova pressupõem que as questões sejam construídas de maneira a mostrarem sua relação com a sociedade - um contexto. Desse modo, estabeleceu-se que as questões contextuais envolveriam apenas uma disciplina, enquanto as interdisciplinares englobariam várias.

Após a definição dos critérios, empreendeu-se uma análise categorial de conteúdo (BARDIN, 2011) a fim de avaliar a presença de conteúdos que remetessem às disciplinas da área de Ciências Naturais (Química, Física e Biologia). A inferência realizada foi: a predominância de questões contextuais poderia promover um ensino com característica mais disciplinar, pautado na contextualização. Em analogia, a prevalência de questões interdisciplinares teria como resultado a elaboração de práticas docentes que privilegiassem esse tipo de abordagem. 
É esperado que este trabalho mostre que a interação entre as disciplinas que compõem a área de Ciências Naturais pode promover reflexos no desempenho dos estudantes do Novo Enem. Isto é, como poderia ser elaborado um plano de trabalho docente que permitiria ao aluno reconhecer os conteúdos estudados em sala de aula durante a realização do teste.

A relevância social pretendida com este estudo é a de permitir, aos docentes, um olhar mais detalhado sobre a maneira pela qual o Novo Enem é construído em termos de contextualização e interdisciplinaridade. Desta forma, os professores estariam mais aptos a considerarem ou não o formato desse teste em seu planejamento.

O trabalho foi organizado da seguinte forma: no segundo item é descrito o Novo Enem em termos metodológicos com base nos documentos norteadores e trabalhos sobre o exame. Em seguida, é feita a delimitação de interdisciplinaridade e contextualização de acordo com o escopo deste estudo. Para tal se apresentam definições diversas de modo a pautar a escolha realizada. No quarto item é apresentada a metodologia de pesquisa empregada e os critérios compreendidos na análise categorial de conteúdo. No quinto item demonstram-se as análises das questões e a discussão sobre o perfil da avaliação com base no escopo e metodologias empregados. Por fim, são apresentadas as conclusões finais e possíveis implicações do estudo apresentado.

\section{Novo Enem}

O Exame Nacional do Ensino Médio (Enem) foi criado em 1998 como uma forma de avaliação alternativa aos exames vestibulares, pois promove aos egressos do Ensino Médio uma ferramenta de autoavaliação de suas competências e habilidades para a atuação cidadã (ANDRADE, 2012). Em sua concepção, o exame engloba a avaliação de competências e habilidades que estão em consonância com a proposta de ensino desfragmentado e contextualizado preconizada nos Parâmetros Curriculares Nacionais (PCN) (BRASIL, 1999). Sendo assim, o documento básico do Enem (INSTITUTO NACIONAL DE ESTUDOS E PESQUISAS EDUCACIONAIS ANÍSIO TEIXEIRA, 2002) justifica a necessidade de que o estudante egresso do Ensino Médio (EM) tenha desenvolvido habilidades e competências que lhe permitam seguir os diversos caminhos possíveis, após o término da Educação Básica. Desse modo, o exame visa avaliar a capacidade de raciocínio envolvendo temas sociais, econômicos e ambientais em detrimento da memorização de conteúdos desconexos. (INSTITUTO NACIONAL DE ESTUDOS E PESQUISAS EDUCACIONAIS ANÍSIO TEIXEIRA, 2002; MACENO et al., 2011).

Em uma tentativa de unificar o sistema de ingresso dos estudantes no Ensino Superior por meio de Enem, os representantes das Instituições de Ensino Superior (IES) teceram críticas quanto ao caráter genérico da avaliação que não possibilitava verificar o pleno desenvolvimento de conteúdos necessários à continuidade dos alunos no Ensino Superior. Diante desse impasse, surgiu a proposta do Novo Enem, que foi aplicada em 2009 (ANDRADE, 2012; OLIVEIRA et al., 2013). O Novo Enem continuou a ser uma avaliação individual, mas é, agora, estruturada a partir de uma matriz de referência própria (BRASIL, 2009). A avaliação é composta de uma redação dissertativa acerca de temas contemporâneos socialmente relevantes, em conjunto com quatro blocos de 45 questões de múltipla escolha. Embora as demandas das IES tenham sido atendidas, o Novo Enem ainda é pautado em competências e habilidades. (ANDRADE, 2012). 
Para a área Ciências Naturais $(\mathrm{CN})$, em que estão inseridas as disciplinas de Química, Física e Biologia, a Matriz de Referência (BRASIL, 2009) elenca oito competências que englobam, no total, 30 habilidades, evidenciando a possibilidade de contextualização e interdisciplinaridade entre as disciplinas envolvidas, uma vez que 19 habilidades são consideradas não específicas para nenhuma delas. As outras habilidades estão divididas de acordo com a disciplina, constituindo-se a parte específica da prova.

A construção da nova proposta de avaliação do Novo Enem passou a considerar a necessidade de maior domínio de conteúdos curriculares e a possibilidade do ingresso no Ensino Superior elevou consideravelmente o número de alunos inscritos no exame (OLIVEIRA et al., 2013). Um efeito prático desses dois fenômenos, segundo os mesmos autores, é a importância que passou a ser dada ao Novo Enem para a elaboração de materiais didáticos e, em consequência, na prática docente. Considerando esses pontos, é importante que se estude o perfil da avaliação sob diferentes ópticas, de modo a evidenciar como o exame pode influenciar na prática docente.

Nesse contexto, é necessário compreender os diferenciais apresentados pela avaliação em termos de interdisciplinaridade e contextualização, pois, mesmo que seja consenso em trabalhos que avaliam a estrutura no Novo Enem, de que essas características foram minimizadas após a reformulação da prova, é possível identificar elementos que remetam à inclusão dessas abordagens na prática docente (GEBARA et al., 2013; OLIVEIRA et al., 2013; FERNANDES SOBRINHO; SANTOS, 2014). É possível verificar nos trabalhos dos mesmos autores o reconhecimento de uma grande polissemia em relação aos conceitos de interdisciplinaridade e contextualização como estratégias para abordagem do conteúdo, por isso faz-se necessário delimitar que concepção foi escolhida para ser adotada neste estudo.

\section{Interdisciplinaridade vs. Contextualização}

Em relação ao conceito de interdisciplinaridade, Lenoir (1998) estabelece que prática interdisciplinar é aquela que prevê a existência de no mínimo duas disciplinas que dialogam entre si por meio de uma ação recíproca que tem por finalidade a difusão do conhecimento e a formação de atores sociais. Como resultado dessa prática, há o diálogo entre teoria e prática e a discussão do contexto, culminando na parceria entre as disciplinas escolares sob um tema comum, em consonância com os preceitos, prescindindo da participação de mais de um professor em disciplinas diferentes.

Para Fazenda (1991, 2012), a interdisciplinaridade deveria ser entendida mais como um modo de ação e de vivência do que como uma estratégia de estudo do conteúdo. Segundo a autora, uma prática interdisciplinar tem por objetivo principal a unificação dos saberes em torno de um objeto comum de modo a promover a desfragmentação dos conteúdos disciplinares, tornando indispensável que ocorra a articulação do trabalho entre as disciplinas e áreas do conhecimento.

Em analogia a uma orquestra sinfônica, Ferreira (1991) ressalta a concepção de que a principal característica da interdisciplinaridade é a existência de um projeto único em torno de um tema que contará com a cooperação das disciplinas específicas em igual peso e importância, unificando o conhecimento.

Santomé (1998) afirma que a interdisciplinaridade ocorre quando, na construção de um projeto mais geral, as disciplinas envolvidas são modificadas e passam a depender das de- 
mais para promover a compreensão global do assunto que será desenvolvido, proporcionando comunicação intensiva e enriquecimento das disciplinas envolvidas.

Em consonância com as concepções supracitadas, Japiassu (1976) entende que a interdisciplinaridade surgiu da necessidade de superação da fragmentação do conhecimento provocada pelas mudanças ocorridas no século XIX em busca de uma visão unificada do conhecimento. Porém, o autor aponta a necessidade de que haja uma disciplina que coordene o processo de cooperação, isto é, é necessário que uma disciplina hierarquicamente superior administre a participação das outras disciplinas, dirigindo o projeto para o fim esperado.

Os PCN+ (BRASIL, 2002) sugerem que o controle de uma boa prática interdisciplinar pode ser feito por um projeto coletivo e bem estruturado com indicação de metas e encaminhamentos metodológicos, bem como as funções de cada professor, embora este documento oficial indique que a interdisciplinaridade também possa ser feita isoladamente, quando se trata de diferentes disciplinas na aula.

Em consonância com o discutido por Gebara (2009), há discordâncias entre o que se define como interdisciplinaridade, principalmente em relação a como o trabalho conjunto em duas disciplinas deve ser construído. Em contrapartida, um ponto comum entre as definições é a necessidade de um tema em torno do qual serão elencados os conteúdos e os objetivos que se deseja trabalhar.

Diante da divergência entre os conceitos de interdisciplinaridade, assume-se que, neste estudo, interdisciplinaridade é a ação planejada em torno de um projeto comum por mais de uma disciplina, que tem por finalidade a contribuição dos pontos de vista de cada campo do conhecimento e a cooperação conjunta para o entendimento global do assunto que foi escolhido como tema do plano de trabalho. Neste contexto, as questões do Novo Enem figurariam como a fonte do projeto comum que coordenaria a ação das disciplinas envolvidas em torno da sua resolução.

Uma prática interdisciplinar, de acordo com o definido e apoiado nos conceitos defendidos por Lenoir (1998) e Fazenda (1991, 2012), é muito complicada de ser abordada em sua plenitude. Diante desse contexto, Augusto e Caldeira (2007) apontam barreiras encontradas por 28 professores de Ciências Naturais de Bauru, SP, que participaram do curso de formação Pró-Ciência, executado em agosto de 2002, para a realização de práticas interdisciplinares, entre elas: a formação disciplinar, a falta de tempo para formação continuada e pesquisa sobre o tema, a falta de confiança, a rotatividade do corpo docente, a falta de apoio metodológico na escola e a postura dos alunos frente a novas metodologias.

Tendo em vista as dificuldades metodológicas e até epistemológicas, como as apontadas no parágrafo anterior, para a aplicação de projetos interdisciplinares, foi observada a tentativa dos professores em abordar os conhecimentos prévios dos alunos e a relação entre o conteúdo abordado e os contextos de aplicação de forma isolada, dentro de somente uma disciplina praticando a contextualização. (AMORIM; SOUZA, TRÓPIA, 2009).

Já quanto à contextualização, Wartha, Silva e Bejarano (2013) consideram que essa abordagem pode ser entendida como uma prática que visa promover forte relação entre os conteúdos específicos das disciplinas escolares com os conhecimentos prévios do aluno, não apenas no sentido de suas ações e experiências cotidianas, mas a relação do conteúdo e do sujeito com o contexto histórico, social e cultural no qual está inserido, em relação à disciplina, visando formar um cidadão crítico, sem que haja a necessidade de articulação interdisciplinar, ou seja, que envolva outras disciplinas. 
Segundo os PCN+ (BRASIL, 2002), a contextualização no ensino de CN pode ser realizada dentro de cada disciplina sem a necessidade de um projeto interdisciplinar, como também deve promover a relação entre os conceitos trabalhados com a representação e discussão de temas práticos do cotidiano.

Em entrevista com elaboradores dos textos de base do Enem, Fernandes e Marques (2012) também identificaram diversas concepções sobre a maneira de se fazer a contextualização dos conteúdos nas questões que comporiam a prova. Segundo a análise realizada por eles, a contextualização era entendida como uma relação entre contextos, por isso o emprego de trechos de obras, relações ambientais e aplicação do conhecimento em diferentes disciplinas são exemplos dessa abordagem. O objetivo da contextualização seria, então, a problematização dos conceitos que antes seriam trabalhados de maneira isolada.

Sendo assim, para efeitos deste estudo, a contextualização será considerada como uma prática individual, realizada em apenas uma disciplina, na qual são evocadas situações históricas, sociais ou ambientais, bem como exemplos de aplicação em outras áreas do conhecimento. Neste ínterim, a questão do Novo Enem não conteria elementos que possibilitassem de imediato o trabalho conjunto de duas disciplinas, apenas a ação isolada, por disciplina, resolveria o assunto.

A delimitação entre contextualização e interdisciplinaridade foi essencial para a determinação de caráter das questões da prova do Novo Enem, cujo objetivo é concluir quais as possibilidades de interdisciplinaridade e contextualização podem ser construídas a partir das questões do exame, a fim de compreender como o exame pode servir de subsídio para práticas docentes pautadas nesses preceitos.

\section{Análise do caráter interdisciplinar ou contextual das questões do Novo Enem}

O objetivo desta análise foi verificar qual perfil (Interdisciplinaridade ou Contextualização) é mais recorrente nas questões de CN do Novo Enem. Nesta classificação, o termo interdisciplinar refere-se somente à presença de conteúdos de duas disciplinas na questão analisada, uma vez que a presença de duas disciplinas foi considerada essencial para a prática interdisciplinar conforme discutido no item anterior.

Para realizar esse estudo, optou-se pelo emprego da análise categorial dentro dos conceitos da Análise de Conteúdo (BARDIN, 2011). Sendo assim, descrevem-se abaixo os elementos que foram considerados na organização da análise categorial realizada: (1) corpus: todas as questões da área de conhecimento de $\mathrm{CN}$ dos cadernos azuis que compuseram as avaliações do Enem de 2009 a 2014 (totalizando 270 questões); (2) unidade de registro: palavra; (3) regra de enumeração: presença; (4) unidade de contexto: livros didáticos aprovados pelo Programa Nacional do Livro Didático (PNLD) 2015 (BRASIL, 2014), escolhidos na escola onde um dos autores deste artigo atuou como professor no momento do estudo: "Química cidadã" (SANTOS; MÓL, 2013), "Biologia hoje" (LINHARES; GEWANDSZNAJDER, 2013), e "Física para o ensino médio" (KAZUHITO; FUKE, 2013); (5) critério de categorização: semântico; (6) indicadores: conteúdos disciplinares descrito nos PCN+ (BRASIL, 2002); (7) categorias e subcategorias: disciplinar (Química, Física e Biologia) e interdisciplinar (Química e Biologia; Química e Física, Física e Biologia). 
Portanto, as questões foram analisadas pela presença de palavras que se relacionavam com os conteúdos descritos nos PCN+ (BRASIL, 2002), desde que fossem abordados nos livros didáticos escolhidos como unidade de contexto. A escolha dos livros didáticos aprovados pelo PNLD, como unidade de contexto, foi necessária para que houvesse um critério definido para relacionar os conteúdos citados na prova com aqueles trabalhados em sala de aula. Essa escolha pode ser considerada como uma inferência, desde que a presença dos conteúdos no livro didático indica que há maior probabilidade de serem abordados pelo professor durante as aulas.

A presença dos indicadores nas questões (enunciado e alternativas) levará à categorização da seguinte maneira: (1) se o enunciado e as alternativas da questão analisada apresentarem apenas conteúdos indicados de uma das disciplinas, a mensagem é classificada na categoria disciplinar; (2) se o enunciado e/ou as alternativas da questão analisada apresentarem conteúdos de duas disciplinas, a mensagem será classificada na categoria interdisciplinar.

A inferência aplicada está calcada na própria mensagem, ou seja, caso ela seja classificada como disciplinar, promoverá uma abordagem disciplinar (contextualização) do conteúdo em sala de aula e, do contrário, se for interdisciplinar, possivelmente promoverá uma atuação interdisciplinar.

\section{Caracterização das questões do Novo Enem: Interdisciplinares ou Contextuais?}

As questões de $\mathrm{CN}$ do Novo Enem puderam ser classificadas de acordo com o(s) componente(s) curricular(es) envolvido(s) no processo de resolução, conforme a Tabela 1, compondo as subcategorias e categorias de análise propostas no item anterior.

Tabela 1. Classificação das Questões por Disciplina

\begin{tabular}{|c|c|c|c|c|c|c|c|c|c|}
\hline \multirow{2}{*}{ Categoria } & \multirow{2}{*}{ Subcategoria } & \multicolumn{6}{|c|}{ Ano de aplicação } & \multirow{2}{*}{\multicolumn{2}{|c|}{$\%$}} \\
\hline & & 2009 & 2010 & 2011 & 2012 & 2013 & 2014 & & \\
\hline \multirow{3}{*}{ Disciplinar } & Química & 10 & 14 & 7 & 12 & 15 & 14 & 27 & \\
\hline & Física & 13 & 12 & 14 & 16 & 15 & 14 & 31 & 87 \\
\hline & Biologia & 15 & 10 & 17 & 13 & 13 & 11 & 29 & \\
\hline \multirow{3}{*}{ Interdisciplinar } & Química e Biologia & 3 & 7 & 6 & 3 & 2 & 6 & 10 & \\
\hline & Química e Física & 2 & 2 & 1 & 1 & 0 & 0 & 2 & 13 \\
\hline & Física e Biologia & 2 & 0 & 0 & 0 & 0 & 0 & 1 & \\
\hline \multicolumn{2}{|c|}{ Total } & 45 & 45 & 45 & 45 & 45 & 45 & 100 & 100 \\
\hline
\end{tabular}

Fonte: elaborada pelos autores.

Com base na Tabela 1, é possível observar que as questões puderam ser divididas em duas categorias compostas por três subcategorias cada, de acordo com as disciplinas do Ensino Médio consideradas de maneira isolada (Química, Física e Biologia) ou com ocorrência de interdisciplinaridade (Química e Física, Química e Biologia e Física e Biologia). 
Apesar da variação do número de questões de cada disciplina em cada ano e a predominância de questões classificadas em Física (31\%), em relação a 27\% em Biologia e 21\% em Química, a representatividade de cada disciplina é equivalente. Essa divisão era esperada, tendo em vista a proposta de a avaliação ser por área. A menor incidência de questões das disciplinas de Química e Biologia, comparada às de Física, pode ser explicada pelo número maior de questões interdisciplinares que envolvem essas duas disciplinas. Em contrapartida, observam-se menos ocorrências de questões interdisciplinares envolvendo Física, com destaque para a categoria Física e Biologia, que representa menos de $1 \%$ da prova e foi identificada apenas na prova de 2009.

As questões de cunho interdisciplinar (13\%), contudo, somam uma parte menos expressiva que as questões disciplinares da avaliação (87\%), o que demonstra que, apesar do que é estabelecido pelos PCN+ (BRASIL, 2002), a interdisciplinaridade não é prática recorrente nas questões, explicitando a fragmentação do conteúdo.

Sendo assim, é possível perceber que, nos anos de 2009 a 2014, o caráter predominante das questões da prova é disciplinar e infere-se que esse perfil se reflete no trabalho dos professores em sala de aula, pois a prova do Novo Enem é utilizada pelos professores como um parâmetro para a construção do planejamento. (FAZENDA, 1991, 2012; LENOIR, 1998).

Algumas questões, no entanto, se tornaram difíceis de serem classificadas pelos autores deste estudo, causando divergência de opiniões quanto à categoria na qual deveriam ser incluídas. Algumas delas foram tomadas para discussão mais aprofundada, visando mostrar as dificuldades que se apresentaram na classificação dessas questões.

Em suma, o principal ponto de discussão foi feito em relação ao caráter interdisciplinar da questão. Conflitos em classificar questões como interdisciplinares ou apenas contextuais podem ser causados pela diversidade de definições e pressupostos metodológicos acerca da interdisciplinaridade e contextualização como práticas de ensino em sala de aula. O ponto principal na decisão sobre a classificação final dessas questões foi a possível utilização em sala de aula.

A questão 8 do caderno azul da prova de 2009 (EXAME..., 2009) foi classificada na categoria de Física e Biologia, por relacionar-se aos conteúdos: Uso social da energia e Ecossistemas. Contudo, nenhum dos livros analisados trata do funcionamento das usinas hidrelétricas e de seus impactos ambientais, cabendo ao professor da disciplina promover a discussão sem o apoio do material didático (o que evidencia a necessidade de materiais voltados para essa abordagem). O tipo de discussão necessária para entender esse tipo de questão deveria envolver uma abordagem interdisciplinar, na investigação dos problemas, causados pela instalação desse tipo de usina, pois os temas tratados são bastante diversos para serem trabalhados por um só professor. A sugestão seria um projeto interdisciplinar envolvendo Química, Física, Biologia e Geografia, devido a sua citação nos livros dessas disciplinas.

A questão 37 do caderno azul da prova de 2009 (EXAME..., 2009) trata da percepção da luz pelo olho humano em relação às células que a percebem. Apesar de, ao final da discussão, ela ter sido classificada como Física e Biologia, o livro de Física escolhido não faz qualquer menção à estrutura celular envolvida nesse fenômeno sensorial, e, nesse caso, sugere-se uma abordagem contextual para as aulas de Física. O livro de Biologia, por sua vez, não faz menção ao comportamento da radiação, mas relaciona a estrutura celular e a questão das cores envolvidas. Essa questão, portanto, poderia ser considerada de Biologia. 
Na questão 66 do caderno azul da prova de 2010 (EXAME..., 2010), o assunto tratado foi respiração celular anaeróbica o que é um conteúdo ligado à Biologia. Contudo, a resolução da questão está ligada à Química no que se refere à capacidade das espécies químicas que podem ser aceptores finais de elétrons em substituição ao hidrogênio. Esse tema, no livro de Biologia, não chega ao nível de aprofundamento necessário para responder essa questão. Os estudos de Química podem ser considerados suficientes para respondê-la, pois o enxofre é da família do oxigênio, tendo propriedades semelhantes a ele, e o ânion nitrato também teria tendência em formar o trióxido de nitrogênio. Por meio dessa análise, a questão foi classificada como somente Química, mas a questão contextual poderia dificultar a relação direta com a Química, por isso uma abordagem interdisciplinar, citando os ciclos biogeoquímicos, poderia facilitar a relação entre as reações de oxidação e respiração celular.

A questão 71 do caderno azul da prova de 2011 (EXAME..., 2011) foi classificada como apenas de Física por se enquadrar no conteúdo do uso social da energia e não abordar explicitamente outros conteúdos de Química ou Biologia. Contudo, a análise do livro de Física não apresenta discussões aprofundadas envolvendo os combustíveis. Uma abordagem muito contextualizada em quaisquer das disciplinas poderia levar a compreensão do tema, porém, a prática docente dos autores deste trabalho, em instituições públicas de ensino médio, mostra que não há casos em que discussões tão específicas tenham sido tratadas pelas disciplinas de CN. É um exemplo de questão centrada em uma controvérsia real e que, portanto, necessita de conhecimentos de várias áreas para a tomada de decisão coerente e consistente. Um tipo de prática que poderia levar a uma aprendizagem crítica, relacionando tantos pontos distintos, seria um trabalho interdisciplinar entre as disciplinas da área e a disciplina de Geografia.

Na questão 83 do caderno azul da prova de 2011 (EXAME..., 2011) o assunto abordado é a poluição ambiental relacionada à produção de etanol. A questão foi classificada em Química e Biologia, pois trata da questão ambiental e dos ciclos biogeoquímicos. Contudo, a análise mais aprofundada da questão sugere que ela não seria muito utilizada por professores de Biologia, pois trata de mais conceitos químicos (como o $\mathrm{pH}$ ) e o estudo dos micro-organismos envolvidos nos ciclos biogeoquímicos, que também é visto em Química, mesmo com uma abordagem mais tradicional, permitindo a classificação como somente de Química e evidenciando que a presença de menções de assuntos de domínios não torna a questão atrativa para ser estudada, tratando-se apenas de um assunto de contextualização.

Os principais problemas relacionados à classificação das questões são acerca da simples contextualização da questão - nesse caso, apesar de o enunciado citar elementos de outras disciplinas, seria apenas como elemento ilustrativo e contextual, não sendo imprescindível para a resolução - ou no caso de disciplinas que envolvem controvérsias muito complexas que necessitariam de uma abordagem interdisciplinar entre Química, Física e Biologia e disciplinas de outras áreas, como Geografia. A falta de estudos que abordem esse tipo de análise indica a importância de se atentar em como as avaliações e as práticas docentes estão sendo conduzidas, para que haja coerência entre elas.

A partir dessa categorização foi possível perceber que, além do caráter disciplinar da prova, algumas questões propõem relações muito avançadas e distante do que ocorre em sala de aula, indicando a necessidade de se reavaliar a proximidade entre o que se ensina no Ensino Médio e o exame destinado a avaliá-lo. 


\section{Considerações Finais}

Após a classificação do perfil das questões em relação à interdisciplinaridade e contextualização e a comparação com a literatura, foi possível observar incongruências com o que era esperado para o perfil da prova. Além disso, uma vez que a maioria das suas questões apresenta caráter disciplinar, infere-se que pode ocorrer desmotivação para a prática interdisciplinar descrita nos PCN+. (BRASIL, 2002).

O emprego de questões com caráter interdisciplinar na prova do Novo Enem era esperado, pois promove a possibilidade de utilização das competências gerais a serem desenvolvidas pelos egressos do Ensino Médio: domínio de linguagens, compreensão de fenômenos, enfrentamento de situações problema, construção de argumentos e elaboração de propostas. O mais frequente, contudo, foram questões entendidas como exclusivamente propedêuticas, ou seja, que não apresentavam o conteúdo de Química de maneira socialmente relevante. Além disso, a característica pouco interdisciplinar da prova indica que a contextualização, isto é, a utilização de outros contextos para exemplificar a relação do conteúdo com aspectos sociais, econômicos e ambientais é suficiente para que os alunos estudantes consigam resolver a avaliação.

É necessário, de acordo com o observado, estudar de maneira mais aprofundada as congruências e distanciamentos entre o que é previsto oficialmente, o que é abordado em sala de aula e o que é apresentado na avaliação. Em outras palavras, percebeu-se que há discrepância entre o currículo proposto, os conteúdos apresentados pelos docentes, e o estilo de avaliação empregado no Novo Enem. Uma unidade neste sentido pode promover melhorias significativas no processo de ensino e aprendizagem de $\mathrm{CN}$ ao oferecer um currículo coerente com a avaliação e possível de ser implementado e desenvolvido pelos professores.

\section{Referências}

AMORIM, F.; SOUZA, C. O.; TRÓPIA, G. Interdisciplinaridade, contextualização e pesquisa-ação: influência de um curso de formação continuada de professores de ciências na prática docente. In: ENCONTRO NACIONAL DE PESQUISA EM ENSINO EM CIÊNCIAS, ENPEC, 7., 2009, Florianópolis. Atas... Disponível em: < http://posgrad.fae. ufmg.br/posgrad/viienpec/pdfs/836.pdf>. Acesso em: 6 abr. 2017.

ANDRADE, G. G. A metodologia do Enem: uma reflexão. Série-Estudos, Campo Grande, n. 33, p. 67-76, 2012. Disponível em: <http://www.serie-estudos.ucdb.br/index.php/serieestudos/article/view/71>. Acesso em: 6 abr. 2017.

AUGUSTO, T. G. S.; CALDEIRA, A. M. A. Dificuldades para a implantação de práticas interdisciplinares em escolas estaduais, apontadas por professores da área de ciências da natureza. Investigações em Ensino de Ciências, Porto Alegre, v. 12. n. 1, p. 139-154, 2007. Disponível em: <http://www.if.ufrgs.br/ienci/artigos/Artigo_ID165/v12_n1_a2007. pdf>. Acesso em: 6 abr. 2017.

BARDIN, L. Análise de conteúdo. São Paulo: Edições 70, 2011. 
O perfil das questões de ciências naturais do novo Enem: ...

BRASIL. Lei no 9.394 de 20 de dezembro de 1996. Estabelece as diretrizes e bases da educação nacional. Diário Oficial da União, Brasília, 23 dez. 1996. Disponível em: <http://www.planalto.gov.br/ccivil_03/leis/L9394.htm>. Acesso em: 10 abr. 2017.

BRASIL. Ministério da Educação. Guia de livros didáticos: PNLD 2015: ensino médio: química. Brasília, 2014. Disponível em: < http://www.fnde.gov.br/programas/livro-didatico/ guias-do-pnld/item/5940-guia-pnld-2015>. Acesso em: 10 abr. 2017.

Matriz de referência do ENEM 2009. Brasília, 2009. Disponível em: <http:// portal.mec.gov.br/dmdocuments/matriz_referencia_novoenem.pdf $>$. Acesso em: 6 abr. 2017.

Parâmetros curriculares nacionais: ensino médio. Brasília, [1999]. Disponível em: <http://portal.mec.gov.br/seb/arquivos/pdf/ciencian.pdf>. Acesso em: 6 abr. 2017.

PCN+ ensino médio: orientações educacionais complementares aos parâmetros curriculares nacionais: cências da natureza, matemática e suas tecnologias: Brasília, [2002]. Disponível em: < http://portal.mec.gov.br/seb/arquivos/pdf/CienciasNatureza.pdf>. Acesso em: 6 abr. 2017.

EXAME nacional do ensino médio 2009: $1^{\circ}$ dia caderno 1 azul. [S.l.: s.n.], 2009. Disponível em: <http://download.inep.gov.br/educacao_basica/enem/downloads/2009/dia1_ caderno1.pdf>. Acesso em: 6 abr. 2017.

EXAME nacional do ensino médio 2010: $1^{\circ}$ dia caderno 1 azul. [S.1.: s.n.], 2010. Disponível em: <http://download.inep.gov.br/educacao_basica/enem/provas/2010/AZUL_Sabado_ GAB.pdf>. Acesso em: 6 abr. 2017.

EXAME nacional do ensino médio 2011: $1^{\circ}$ dia caderno 1 azul. [S.1.: s.n.], 2011. Disponível em: <http://download.inep.gov.br/educacao_basica/enem/provas/2011/01_AZUL_GAB. pdf>. Acesso em: 6 abr. 2017.

FAZENDA, I. C. A. Interdisciplinaridade: definição, projeto, pesquisa. In: . (Coord.).

Práticas interdisciplinares na escola. São Paulo: Cortez, 1991. p. 15-18.

Interdisciplinaridade: história, teoria e pesquisa. Campinas: Papirus, 2012.

FERNANDES, C. S.; MARQUES, C. A. A contextualização no ensino de ciências: a voz de elaboradores de textos teóricos e metodológicos do Exame Nacional do Ensino Médio. Investigações em Ensino de Ciências, Porto Alegre, v. 17. n. 2, p. 509-527, 2012. Disponível em: <https://www.if.ufrgs.br/cref/ojs/index.php/ienci/article/view/201/136>. Acesso em: 6 abr. 2017.

FERNANDES SOBRINHO, M.; SANTOS, W. L. P. Inserções da interdisciplinaridade e contextualização em itens do Enem/2013 com potencial ao enfoque CTS. Uni-pluri/ versidad, Medellín, v. 14, n. 3, p. 94-101, 2014. Disponível em: <https:/ /aprendeenlinea. udea.edu.co/revistas/index.php/unip/article/view/21343/17743>. Acesso em: 6 abr. 2017.

FERREIRA, S. L. Introduzindo a noção de interdisciplinaridade. In: FAZENDA, I. (Coord.). Práticas interdisciplinares na escola. São Paulo: Cortez, 1991. p. 33-35. 
GEBARA, M. J. F. A formação continuada de professores de ciências: contribuições de um curso de curta duração com tema geológico para uma prática de ensino interdisciplinar. 2009. 314 f. Tese (Doutorado em Ciências) - Instituto de Geociências, Universidade Estadual de Campinas, Campinas, 2009.

GEBARA, M. J. F. et al. Ciências da natureza e interdisciplinaridade: a percepção dos estudantes sobre questões de avaliações de larga escala. Enseñanza de las Ciencias, Barcelona, n. extra, p. 1539-1545, 2013. Disponível em: <http://www.raco.cat/index.php/ Ensenanza/article/view/307307/397281>. Acesso em: 6 abr. 2017.

INSTITUTO NACIONAL DE ESTUDOS E PESQUISAS EDUCACIONAIS ANÍSIO TEIXEIRA. ENEM: exame nacional do ensino médio: documento básico 2002. Brasília, 2002. Disponível em: < http://www.publicacoes.inep.gov.br/portal/download/265>. Acesso em: 6 abr. 2017.

JAPIASSU, H. Interdisciplinaridade e a patologia do saber. Rio de Janeiro: Imago, 1976.

KAZUHITO, Y.; FUKE, L. F. Física para o ensino médio. 3 ed. São Paulo: Saraiva, 2013.

LENOIR, Y. Didática e interdisciplinaridade: uma complementaridade necessária e incontrolável. In: FAZENDA, I. C. A. Didática e interdisciplinaridade. Campinas: Papirus, 1998. p. 45-75.

LINHARES, S.; GEWANDSZNAJDER, F. Biologia hoje. 2. ed. São Paulo: Ática, 2013.

MACENO, N. G. et al. A matriz de referência do ENEM 2009 e o desafio de recriar o currículo de química da educação básica. Química Nova na Escola, São Paulo, v. 33, n. 3, p. 153-159, 2011. Disponível em: < http://qnesc.sbq.org.br/online/qnesc33_3/153EA09210.pdf $>$. Acesso em: 6 abr. 2017.

OLIVEIRA, C. F. et al. Contextualização e desempenho em exames de ciências da natureza: o "novo Enem". In: ENCONTRO NACIONAL DE PESQUISA EM EDUCAÇÃO EM CIÊNCIAS, ENPEC, 9., 2013, Água de Lindóia. Atas... Disponível em: < http:/ / sites.ifi. unicamp.br/kleinke/files/2014/01/Contextualizacao-e-desempenho-no-novo-Enem.pdf>. Acesso em: 6 abr. 2017.

SANTOMÉ, J. T. Globalização e interdisciplinaridade: o currículo integrado. Porto Alegre: Artmed, 1998.

SANTOS, W. L. P; MÓL, G. Química cidadã. 2. ed. São Paulo: AJS, 2013.

WARTHA, E. J.; SILVA, E. L.; BEJARANO, N. R. R. Cotidiano e contextualização no ensino de química. Química Nova na Escola, São Paulo, v. 35, n. 2, p. 84-91, 2013.

Disponível em: < http://qnesc.sbq.org.br/online/qnesc35_2/04-CCD-151-12.pdf>. Acesso em: 6 abr. 2017.

Artigo recebido em: 24/05/2016. Aceito em: 13/10/2016.

Endereço para contato: Universidade Tecnológica Federal do Paraná,

Av. Sete de Setembro, 3165, CEP 80230-90, Curitiba, PR, Brasil. 